Supporting Information for

\title{
A numerical model study of the main factors contributing to hypoxia and its sub-seasonal to interannual variability off the Changjiang
}

\section{Estuary}

\author{
Haiyan Zhang ${ }^{1,2}$, Katja Fennel ${ }^{1}$, Arnaud Laurent ${ }^{1}$, Changwei Bian ${ }^{3}$ \\ ${ }^{1}$ Department of Oceanography, Dalhousie University, Halifax, Nova Scotia, Canada \\ ${ }^{2}$ School of Marine Science and Technology, Tianjin University, Tianjin, China \\ ${ }^{3}$ Physical Oceanography Laboratory/CIMST, Ocean University of China, and Qingdao National \\ Laboratory for Marine Science and Technology, Qingdao, China
}

\section{Model-data comparisons of temperature and salinity}

The model reproduces remotely sensed spatial and temporal SST patterns (from the NOAA AVHRR sensor; https://www.nodc.noaa.gov/SatelliteData/ghrsst/) very well with monthly correlation coefficients of 0.89 and above (Figure S1). Simulated surface salinity also shows similar spatial and seasonal pattern as available in situ data (Figure S2) with a correlation coefficient of 0.84 . Both the model and observations indicate that the CDW is confined to the coast south of the estuary in early spring (March 2011) and autumn (October 2013) and extends eastward and northeastward in summer. Some interannual variations occur, e.g., the CDW extends northward and eastward in June 2012 while it mainly spreads southeastward in June 2013.

At the bottom, freshwater is confined to the coast with high-salinity water coming from the open ocean (Figure S3). The correlation coefficient between simulated and observed bottom salinity is 0.87. Simulated bottom temperature shows significant seasonal variations consistent with the observations (Figure S4) with a correlation coefficient of 0.88 . Higher temperature in south and east regions in March indicates the commencement of Kuroshio intrusion onto shelves. 


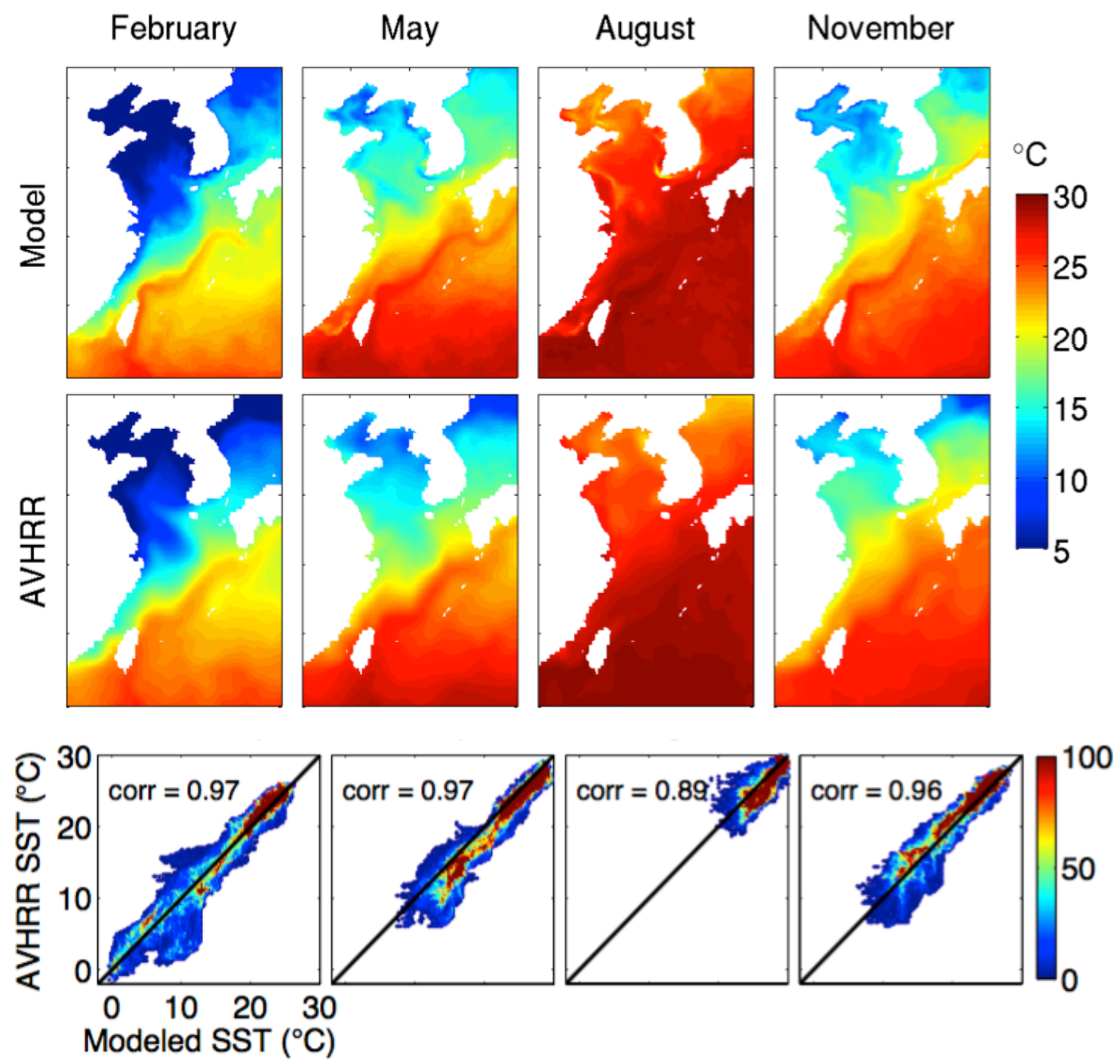

Figure S1. Monthly averaged (2008-2013) SST in the model (top row) and from NOAA AVHRR (row below) in February, May, August and November. 2-dimensional histograms (bottom row) show the corresponding comparisons between model SST and AVHRR SST with correlation reported in each panel. The 1-to-1 line is shown in black. The color scale of the bottom row indicates the number of data pairs in each bin. 

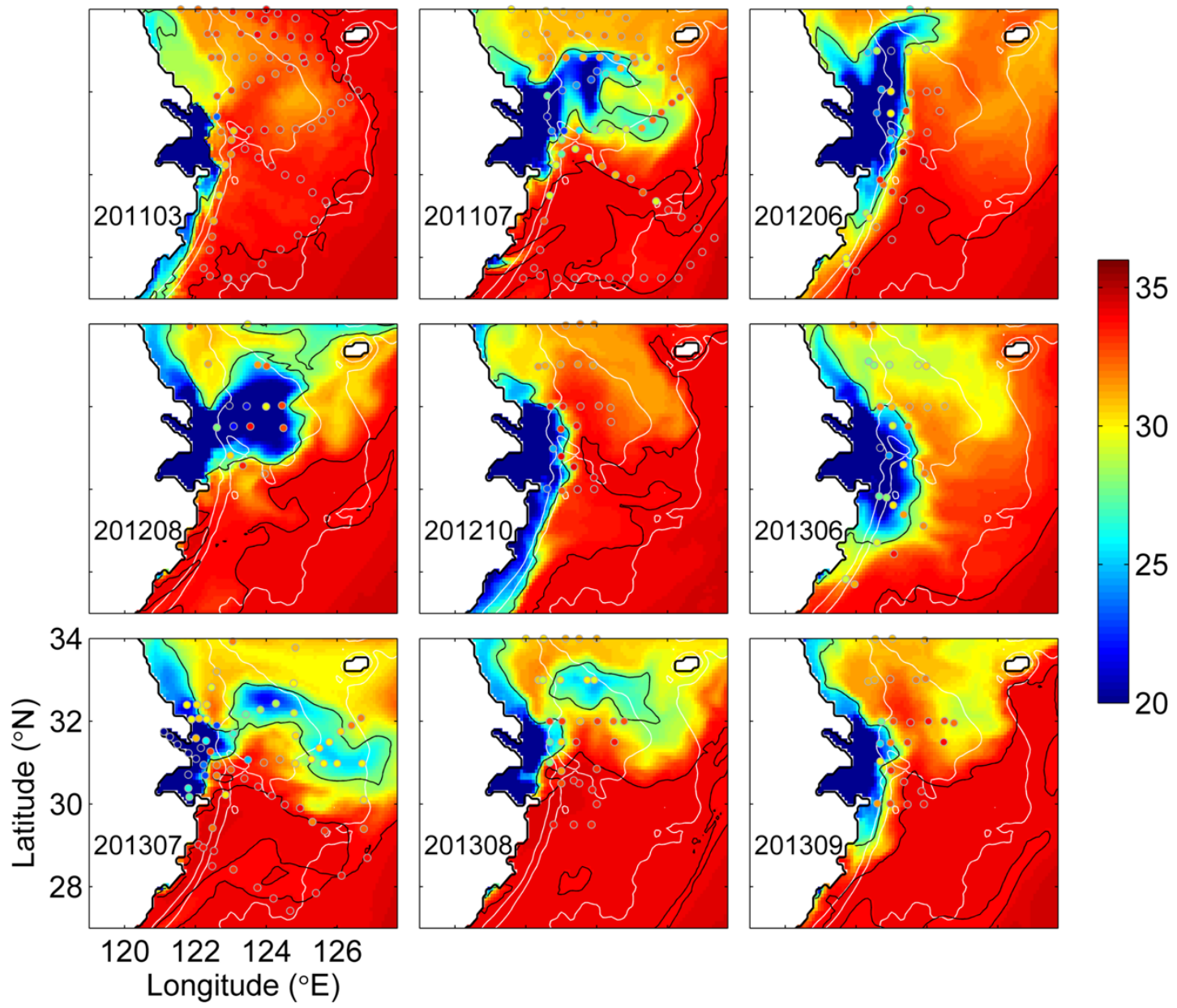

Figure S2. Simulated surface salinity (map) compared with observations (dots) during nine cruises from 2011 to 2013. 

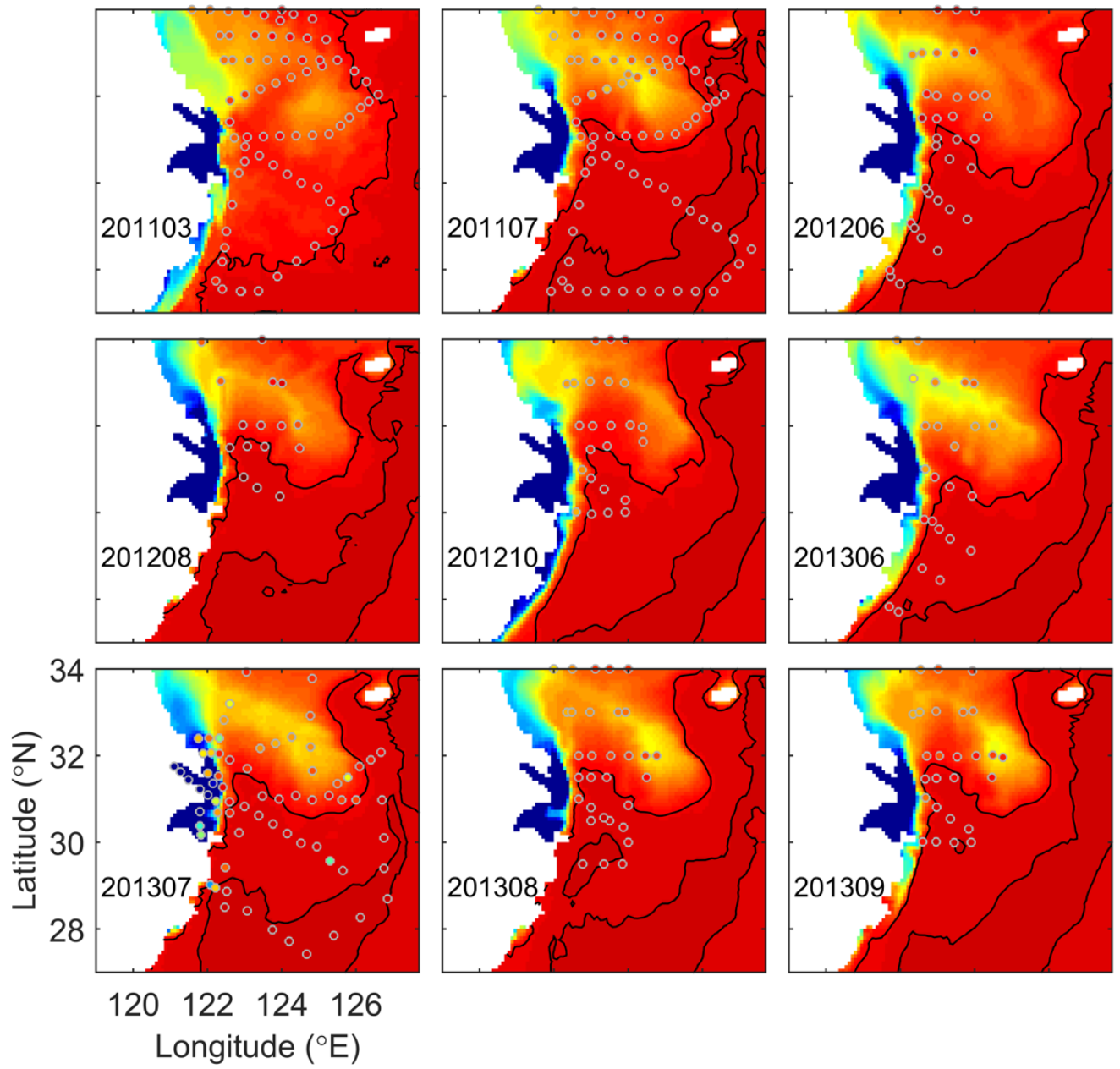

Figure S3. The same as Figure S2 except for bottom salinity. 


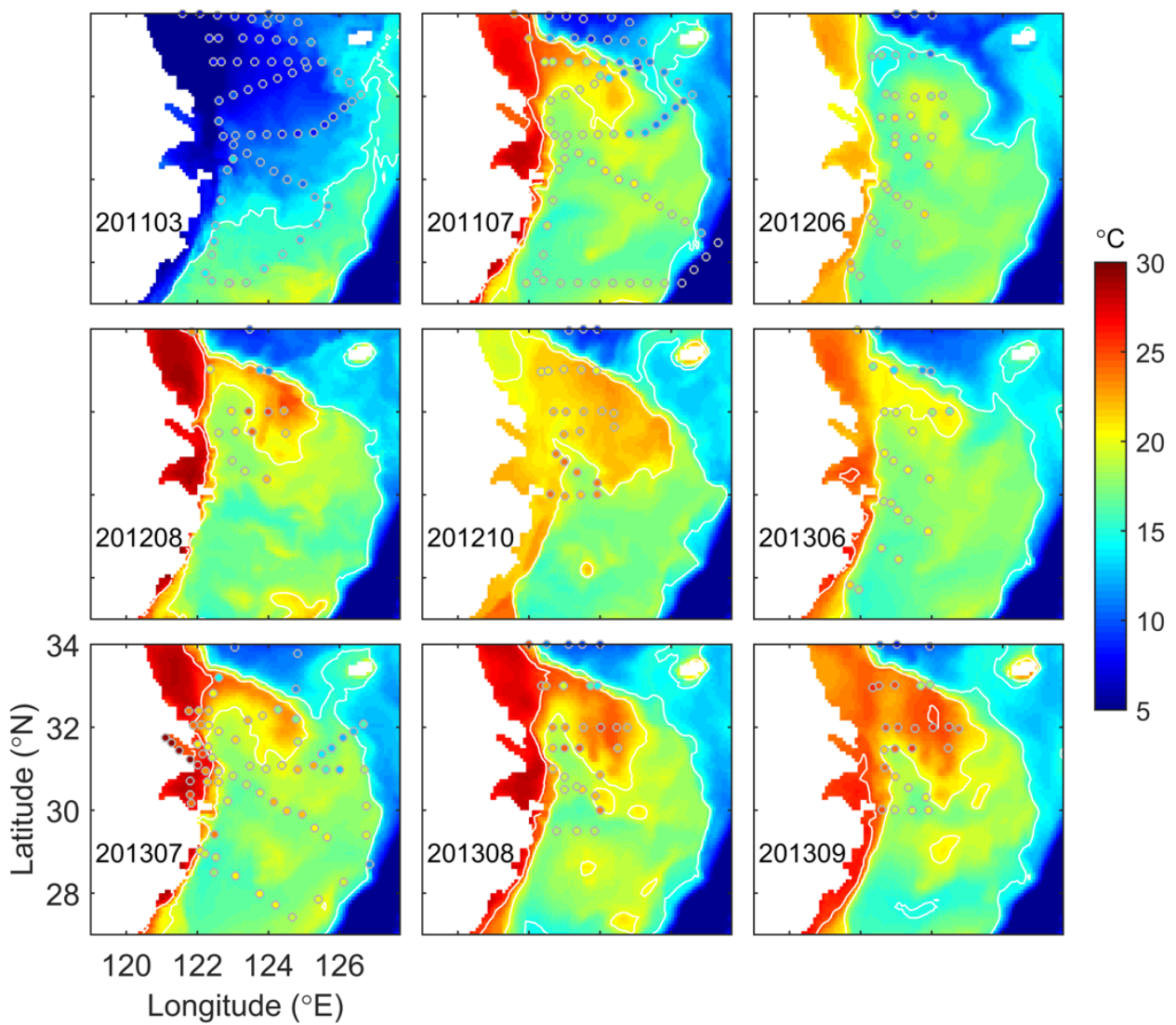

Figure S4. The same as Figure S2 except for bottom temperature.

\section{Assessment of the dominant currents}

The simulated current systems in the ECS, YS and BS show typical seasonal variations (Figure S5). In winter, currents mainly flow southward on the YS and ECS shelves driven by the northerly wind. In contrast, the East China Sea Coastal Current (ECSCC) and the Korean Coastal Current (KCC) flow northward in summer. The Kuroshio is stronger in summer than in winter. Overall, the model captures the seasonal pattern of the current system and resolves currents in the ECS, YS and BS. Simulated volume transports through the Taiwan Strait (TS) and Korea Strait (KS) are $1.09 \pm 0.73 \mathrm{~Sv}$ and $2.58 \pm 0.93 \mathrm{~Sv}$, respectively. Previous studies using in situ observations and numerical models reported volume transport through the TS ranging from 0.42 to $2.3 \mathrm{~Sv}$ (Hu et al., 2010), and an average transport of 1.27 Sv during 1993-2001 based on AVISO SSH data (Guo et al. 2005). The average transport through the KS obtained from ADCP observations is about 2.60-2.65 Sv (Takikawa and Yoon, 2005; Fukudome et al., 2010). The simulated transports in this study are consistent with these previous estimates. 

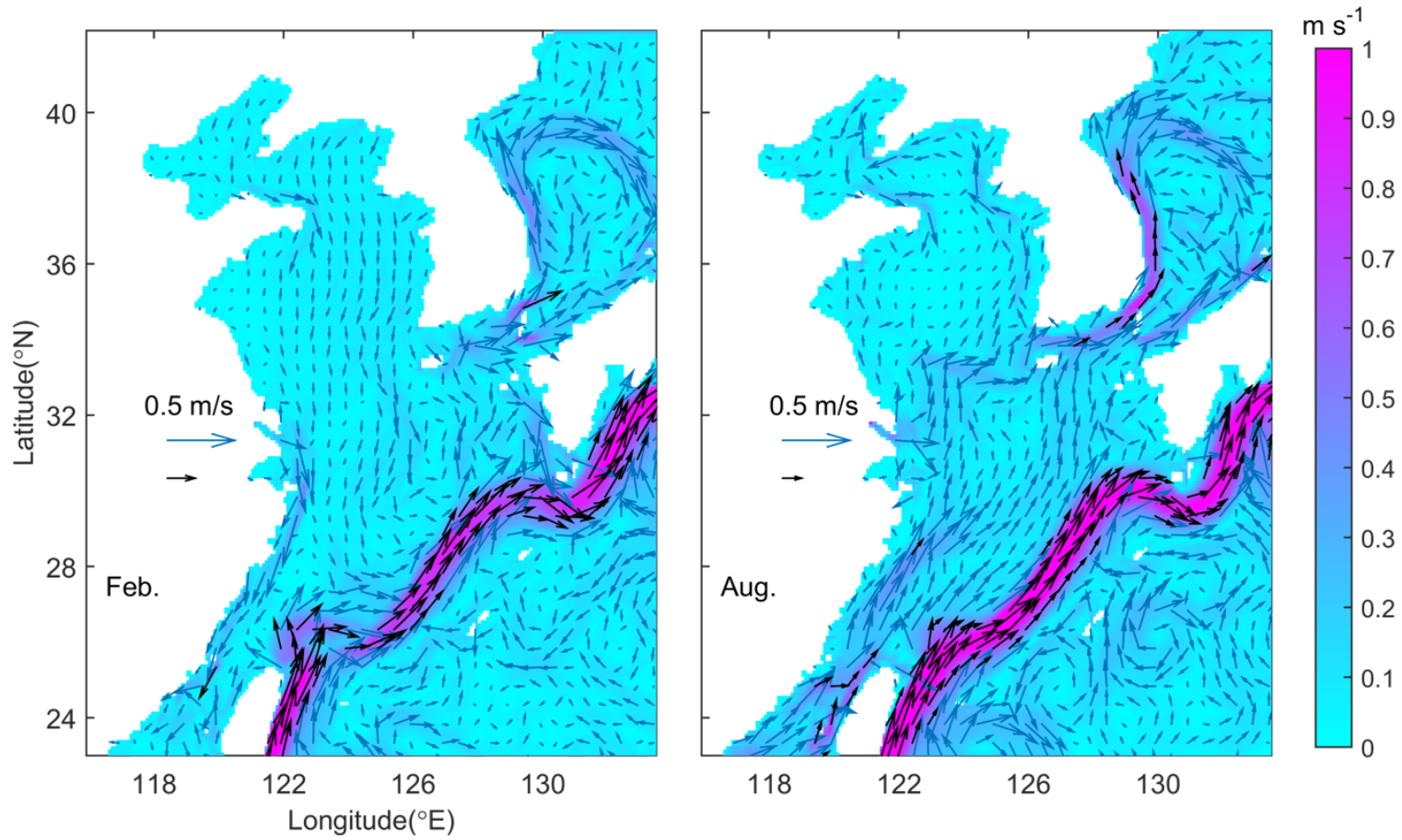

Figure S5. Simulated monthly mean surface currents in February and August. Black arrows represent currents with velocity $>=0.4 \mathrm{~m} / \mathrm{s}$, while blue arrows denote velocity $<0.4 \mathrm{~cm} / \mathrm{s}$.

\section{Model-data comparisons of surface chlorophyll}

Simulated monthly averaged (2008-2013) surface chlorophyll concentrations in four seasons (February, May, August and November) are compared with satellite-derived fields (from the MODIS-Terra sensor; http://oceancolor.gsfc.nasa.gov/) and agree reasonably well in spring, summer and fall (Figure S6). In May, August and November, similar spatial patterns are present in the simulation and satellite data with correlation coefficients of $0.62,0.86$ and 0.58 , respectively. The model slightly overestimates the satellite observations in August and underestimates them in May. In agreement with the observations, simulated surface chlorophyll concentrations are highest in the plume region and decrease offshore. The model underestimates the satellite observations in February, mainly inside the 50-m isobath. One possible reason is that satellite-derived chlorophyll may be overestimated due to high suspended particulate matter concentrations on the inner shelf that result from the strong northerly wind prevailing in wintertime. 

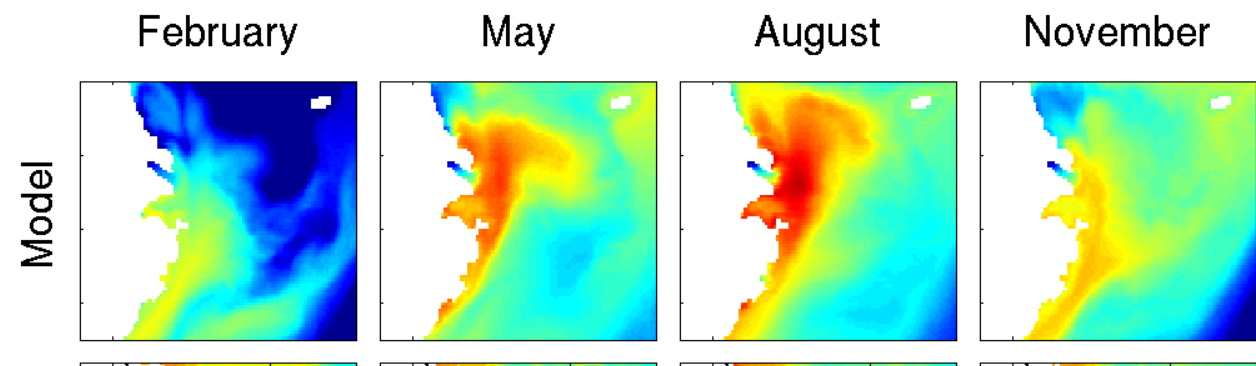

uM
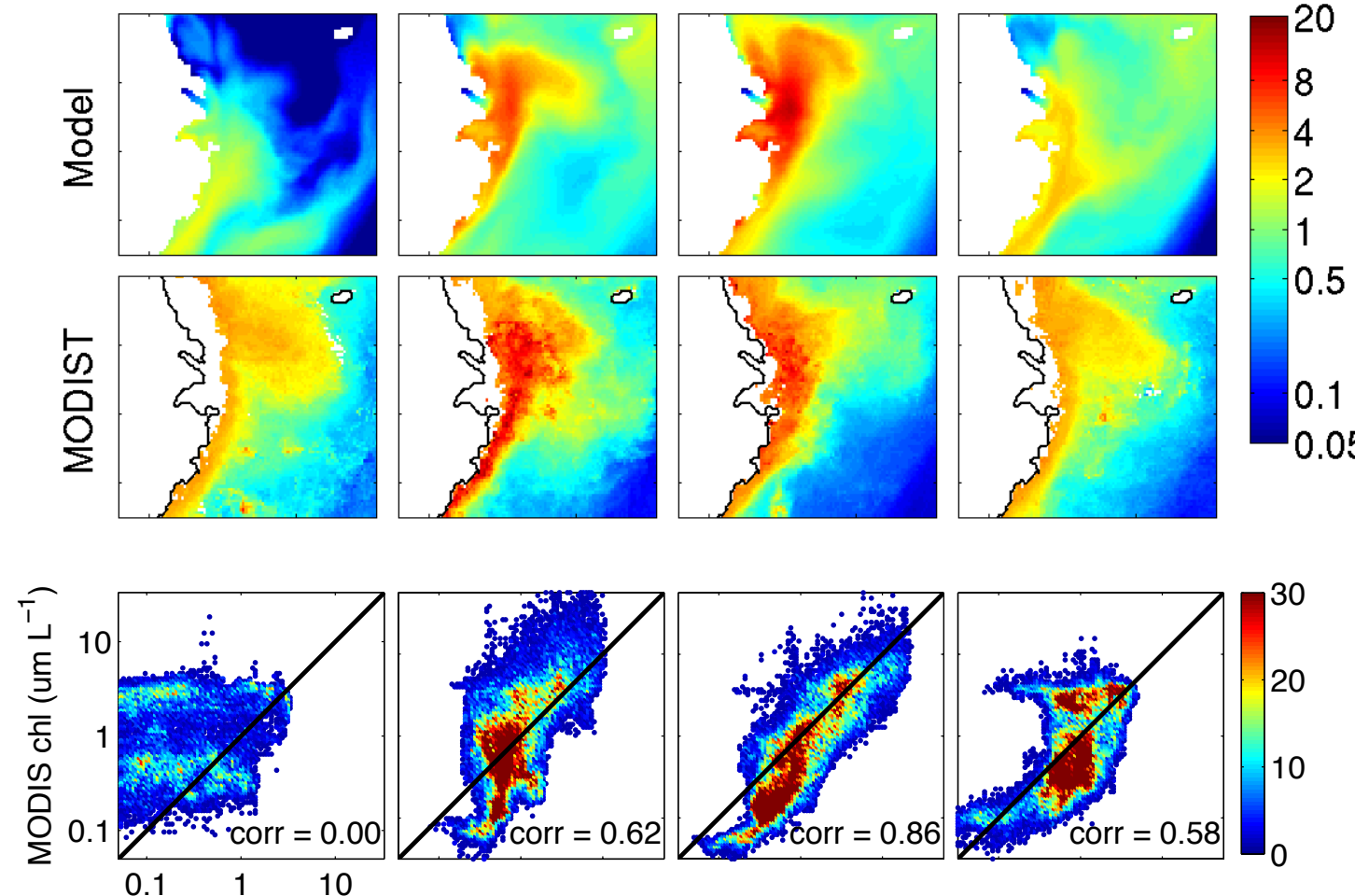

Modeled chl (um L $\left.{ }^{-1}\right)$

Figure S6. The same as Figure S1 except for surface chlorophyll. Observed surface chlorophyll is from MODIS Terra. No observations are available for the white areas near the coast. 


\section{Biogeochemical model parameters}

\begin{tabular}{|c|c|c|c|}
\hline Symbol & Parameter & Value & Units \\
\hline$\mu_{0}$ & phytoplankton growth rate at $0^{\circ} \mathrm{C}$ & 0.59 & $\mathrm{~d}^{-1}$ \\
\hline$k_{\mathrm{NO} 3}$ & half-saturation concentration for uptake of $\mathrm{NO}_{3}$ & 0.5 & $\operatorname{mmol~} \mathrm{N} \mathrm{m}^{-3}$ \\
\hline$k_{N H 4}$ & half-saturation concentration for uptake of $\mathrm{NH}_{4}$ & 0.5 & $\mathrm{mmol} \mathrm{N} \mathrm{m}^{-3}$ \\
\hline$k_{P O 4}$ & half-saturation concentration for uptake of PO4 & 0.03 & $\mathrm{mmol} \mathrm{P} \mathrm{m}^{-3}$ \\
\hline$\alpha$ & initial slope of the P-I curve & 0.025 & $\mathrm{mgC} \mathrm{mgChl}{ }^{-1}\left(\mathrm{~W} \mathrm{~m}^{-2}\right)^{-1} \mathrm{~d}^{-1}$ \\
\hline$k_{I}$ & $\begin{array}{l}\text { light intensity at which the inhibition of } \\
\text { nitrification is half-saturated }\end{array}$ & 0.1 & $\mathrm{~W} \mathrm{~m}^{-2}$ \\
\hline$I_{0}$ & threshold for light-inhibition of nitrification & 0.0095 & $\mathrm{~W} \mathrm{~m} \mathrm{~m}^{-2}$ \\
\hline$m_{P}$ & phytoplankton mortality & 0.15 & $\mathrm{~d}^{-1}$ \\
\hline$\tau$ & aggregation parameter & 0.04 & $\left.(\mathrm{mmol} \mathrm{N} \mathrm{m})^{-3}\right)^{-1} \mathrm{~d}^{-1}$ \\
\hline$\Theta_{\max }$ & maximum chlorophyll to phytoplankton ratio & 0.053 & $\mathrm{mgChl} \mathrm{mgC}^{-1}$ \\
\hline$g_{\max }$ & maximum grazing rate & 0.6 & $\mathrm{~d}^{-1}$ \\
\hline$k_{P}$ & $\begin{array}{l}\text { half-saturation concentration of phytoplankton } \\
\text { ingestion }\end{array}$ & 2 & $(\mathrm{mmol} \mathrm{N} \mathrm{m})^{-3}$ \\
\hline$\beta$ & assimilation efficiency & 0.75 & dimensionless \\
\hline$l_{B M}$ & excretion rate due to basal metabolism & 0.1 & $\mathrm{~d}^{-1}$ \\
\hline$l_{E}$ & maximum rate of assimilation related excretion & 0.1 & $\mathrm{~d}^{-1}$ \\
\hline$m_{Z}$ & zooplankton mortality & 0.1 & $(\mathrm{mmol} \mathrm{N} \mathrm{m})^{-3} \mathrm{~d}^{-1}$ \\
\hline$r_{S D}$ & remineralization rate of suspended detritus & 0.3 & $\mathrm{~d}^{-1}$ \\
\hline$r_{L D}$ & remineralization rate of large detritus & 0.01 & $\mathrm{~d}^{-1}$ \\
\hline$r_{R D}$ & $\begin{array}{l}\text { remineralization rate of riverine dissolved organic } \\
\text { matter }\end{array}$ & 0.03 & $d^{-1}$ \\
\hline$n_{\max }$ & maximum nitrification rate & 0.2 & $\mathrm{~d}^{-1}$ \\
\hline$w_{P h y}$ & sinking velocity of phytoplankton & 0.1 & $\mathrm{~m} \mathrm{~d}^{-1}$ \\
\hline$w_{\text {SDet }}$ & sinking velocity of suspended detritus & 0.1 & $\mathrm{~m} \mathrm{~d}^{-1}$ \\
\hline$w_{\text {LDet }}$ & sinking velocity of larger particles & 5 & $\mathrm{~m} \mathrm{~d}^{-1}$ \\
\hline
\end{tabular}

Table S1 Biological model parameters used in this study. 


\section{Oxygen budget}

\begin{tabular}{|c|c|c|c|c|c|c|c|c|c|c|c|c|c|}
\hline \multirow{2}{*}{$\begin{array}{l}\text { Water } \\
\text { column }\end{array}$} & \multirow[t]{2}{*}{ year } & \multicolumn{6}{|c|}{ northern hypoxic region } & \multicolumn{6}{|c|}{ southern hypoxic region } \\
\hline & & $\begin{array}{l}\text { air- } \\
\text { sea }\end{array}$ & adv & pp & WR & SOC & sum & $\begin{array}{l}\text { air- } \\
\text { sea }\end{array}$ & adv & pp & WR & SOC & sum \\
\hline \multirow{6}{*}{$\begin{array}{l}\text { Whole } \\
\text { column }\end{array}$} & 2008 & -3.08 & -1.89 & 13.95 & -6.93 & -5.37 & -3.31 & -3.92 & -3.17 & 12.93 & -6.01 & -4.71 & -4.87 \\
\hline & 2009 & -2.64 & -1.48 & 15.40 & -7.51 & -5.79 & -2.02 & -3.60 & -1.98 & 13.15 & -6.46 & -4.61 & -3.50 \\
\hline & 2010 & -3.41 & -2.08 & 13.51 & -6.65 & -5.03 & -3.66 & -5.02 & -1.85 & 13.94 & -6.49 & -5.23 & -4.66 \\
\hline & 2011 & -3.26 & -2.41 & 13.82 & -6.76 & -5.34 & -3.95 & -3.85 & -3.30 & 12.31 & -5.90 & -4.32 & -5.05 \\
\hline & 2012 & -3.54 & -1.65 & 13.36 & -6.31 & -5.25 & -3.39 & -3.48 & -3.13 & 12.74 & -5.72 & -4.65 & -4.24 \\
\hline & 2013 & -3.54 & -1.59 & 15.77 & -7.26 & -6.16 & -2.79 & -4.49 & -1.16 & 14.12 & -6.26 & -4.86 & -2.65 \\
\hline & & diff & adv & pp & WR & SOC & sum & diff & adv & $p p$ & WR & SOC & sum \\
\hline \multirow{6}{*}{$\begin{array}{l}\text { Bottom } \\
\text { water }\end{array}$} & 2008 & 6.44 & -1.32 & 1.53 & -3.41 & -5.37 & -2.14 & 2.79 & -0.69 & 0.67 & -1.84 & -4.71 & -3.77 \\
\hline & 2009 & 7.51 & -0.95 & 1.57 & -3.67 & -5.79 & -1.33 & 2.81 & 0.58 & 0.68 & -1.99 & -4.61 & -2.54 \\
\hline & 2010 & 5.87 & -1.61 & 1.42 & -3.22 & -5.03 & -2.58 & 2.50 & 0.82 & 0.53 & -1.94 & -5.23 & -3.32 \\
\hline & 2011 & 6.40 & -1.71 & 1.45 & -3.41 & -5.34 & -2.62 & 2.83 & -1.14 & 0.72 & -1.90 & -4.32 & -3.82 \\
\hline & 2012 & 6.02 & -1.32 & 1.25 & -3.04 & -5.25 & -2.34 & 3.06 & -0.74 & 0.54 & -1.74 & -4.65 & -3.53 \\
\hline & 2013 & 7.36 & -1.01 & 1.54 & -3.70 & -6.16 & -1.97 & 3.00 & 1.47 & 0.72 & -1.99 & -4.86 & -1.67 \\
\hline
\end{tabular}

Table S2. Oxygen budget for the period during which oxygen decreases (March to August) in different years for the whole water column and the bottom water respectively (unit: $\mathrm{mol} \mathrm{O}_{2} \mathrm{~m}^{-2}$ ). 